Supporting Information for

\title{
Stereoselective Synthesis of the Atropisomers of Myristinin B/C
}

\section{David J. Maloney, Shengxie Chen and Sidney M. Hecht*}

General Methods. Reagents and solvents were reagent grade and were used without further purification. Methylene chloride was distilled from calcium hydride, and toluene was distilled from sodium. Anhydrous grade THF and acetonitrile were purchased from VWR. All reactions involving air or moisture sensitive reagents or intermediates were performed under a nitrogen or argon atmosphere. Flash chromatography was performed using Silicycle 40-60 mesh silica gel. Analytical TLC was performed using 0.25 mm EM silica gel $60 \mathrm{~F}_{250}$ plates that were visualized by irradiation $(254 \mathrm{~nm})$ or by staining with vanillin stain. Optical rotations were obtained using a Jasco digital polarimeter. ${ }^{1} \mathrm{H}$ and ${ }^{13} \mathrm{C}$ NMR spectra were obtained using $300 \mathrm{MHz}$ and $500 \mathrm{MHz}$ Varian instruments. Chemical shifts are reported in parts per million $(\mathrm{ppm}, \delta)$ referenced to the residual ${ }^{1} \mathrm{H}$ resonance of the solvent $\left(\mathrm{CDCl}_{3}: 7.26 \mathrm{ppm}, \mathrm{DMSO}-d_{6}: 2.49 \mathrm{ppm}\right) .{ }^{13} \mathrm{C}$ NMR spectra were referenced to the residual ${ }^{13} \mathrm{C}$ resonance of the solvent $\left(\mathrm{CDCl}_{3}: 77.3 \mathrm{ppm}\right.$; DMSO$d_{6}: 39.5 \mathrm{ppm}$ ). Splitting patterns are designed as follows: s, singlet; br, broad; d, doublet; dd, doublet of doublets; t, triplet; q, quartet; m, multiplet. High-resolution mass spectra were obtained at the Michigan State University-NIH Mass Spectrometry Facility. Melting points were determined for all crystalline compounds and are uncorrected. 


\section{Experimental Procedures.}<smiles>O=C(O)c1ccc(C2Cc3ccc([O-])cc3O2)cc1</smiles>

(2R,3S)-7-(Benzoxy)-2-(4-(benzoxy)phenyl)chroman-3-yl Acetate. To a solution containing $0.54 \mathrm{~g}(1.24 \mathrm{mmol})$ of 5 in $10 \mathrm{~mL}$ anhydrous methylene chloride was added $0.51 \mathrm{~g}(0.47 \mathrm{~mL}, 4.96 \mathrm{mmol})$ of $\mathrm{Ac}_{2} \mathrm{O}$ followed by a catalytic amount of 4-N,N dimethylaminopyridine (DMAP). The reaction mixture was stirred at room temperature under $\mathrm{N}_{2}$ for $2 \mathrm{~h}$ then quenched with $50 \mathrm{~mL}$ of water and extracted with three $25-\mathrm{mL}$ portions of methylene chloride. The combined organic layer was washed with $100 \mathrm{~mL}$ of brine, dried $\left(\mathrm{MgSO}_{4}\right)$ and concentrated under diminished pressure. The resulting residue was purified by flash chromatography on a silica gel column $(28 \times 4 \mathrm{~cm})$. Elution with 3:1 hexanes-ethyl acetate gave the product as a colorless oil: yield $0.56 \mathrm{~g}$ (93\%); silica gel TLC $R_{f} 0.53$ (3:1 hexanes-ethyl acetate); $[\alpha]^{22}{ }_{\mathrm{D}}-21.5\left(c 1.4, \mathrm{CHCl}_{3}\right) ;{ }^{1} \mathrm{H} \mathrm{NMR}$ $\left(\mathrm{CDCl}_{3}\right) \delta 2.02(\mathrm{~s}, 3 \mathrm{H}), 2.84(\mathrm{dd}, 1 \mathrm{H}, J=16.2$ and $6.6 \mathrm{~Hz}), 3.05(\mathrm{dd}, 1 \mathrm{H}, J=16.2$ and 5.1 Hz), 5.09 (s, 2H), $5.11(\mathrm{~s}, 2 \mathrm{H}), 5.16(\mathrm{~d}, 1 \mathrm{H}, J=6.0 \mathrm{~Hz}), 5.39(\mathrm{q}, 1 \mathrm{H}, J=5.1 \mathrm{~Hz}), 6.63$ (m, 2H), $7.01(\mathrm{~m}, 3 \mathrm{H}), 7.35(\mathrm{~d}, 2 \mathrm{H}, J=8.7 \mathrm{~Hz})$ and $7.38-7.50(\mathrm{~m}, 10 \mathrm{H}) ;{ }^{13} \mathrm{C} \mathrm{NMR}$ $\left(\mathrm{CDCl}_{3}\right) \delta 21.38,28.57,69.70,70.29,70.35,78.49,102.60,109.06,111.66,115.18$, $127.77,127.80,127.97,128.25,128.30,128.87,130.50,130.69,137.13,137.26,154.66$, 159.00 and 170.50; mass spectrum (FAB), $m / z 481.2014(\mathrm{M}+\mathrm{H})^{+}\left(\mathrm{C}_{31} \mathrm{H}_{29} \mathrm{O}_{5}\right.$ requires 481.2015).

(2S,3R)-7-(Benzoxy)-2-(4-(benzoxy)phenyl)chroman-3-yl Acetate. Identical NMR spectral data as enantiomer. $[\alpha]^{23} \mathrm{D}+22.4\left(c 1.4, \mathrm{CHCl}_{3}\right)$. 


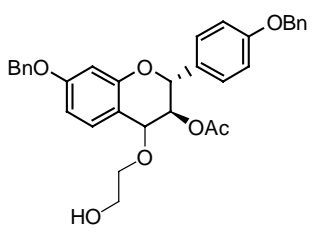

(2R,3S)-2-(4-Benzoxyphenyl)-7-benzoxy-4-(2-hydroxyethoxy)chroman-3-yl Acetate

(6). To a solution containing $2.10 \mathrm{~g}(4.4 \mathrm{mmol})$ of ( $2 R, 3 S)$-7-(benzoxy)-2-(4-

(benzoxy)phenyl)chroman-3-yl acetate in $5 \mathrm{~mL}$ of anhydrous methylene chloride at $0{ }^{\circ} \mathrm{C}$ under $\mathrm{N}_{2}$ was added $2 \mathrm{~mL}$ of ethylene glycol followed by $3.0 \mathrm{~g}$ (13.2 mmol) of DDQ.

The reaction mixture was allowed to stir at room temperature overnight, then cooled to 0 ${ }^{\circ} \mathrm{C}$ and excess 4- $N, N$-dimethylaminopyridine was added. The reaction mixture was stirred at $0{ }^{\circ} \mathrm{C}$ for $15 \mathrm{~min}$, then applied directly to a flash silica gel column $(25 \mathrm{x} 4 \mathrm{~cm})$. Step gradient elution with $3: 1 \rightarrow 1: 2$ hexanes-ethyl acetate gave $0.7 \mathrm{~g}$ of unreacted starting material along with the desired product $\mathbf{6}$ as a colorless foam: yield $1.30 \mathrm{~g}(82 \%)$ (based on consumed starting material); mp $179-181^{\circ} \mathrm{C}$; silica gel TLC $R_{f} 0.32$ (1:1 ethyl acetate-hexanes); $[\alpha]^{22}-29.9\left(c 1.3, \mathrm{CHCl}_{3}\right) ;{ }^{1} \mathrm{H}$ NMR (DMSO- $\left.d_{6}\right) \delta 1.86(\mathrm{~s}, 3 \mathrm{H}), 3.51$ (m, 4H), $3.62(\mathrm{~m}, 1 \mathrm{H}), 4.53(\mathrm{~d}, 1 \mathrm{H}, J=2.0 \mathrm{~Hz}), 4.59(\mathrm{~m}, 1 \mathrm{H}), 5.07(\mathrm{~s}, 2 \mathrm{H}), 5.10(\mathrm{~s}, 2 \mathrm{H})$, $5.30(\mathrm{~s}, 1 \mathrm{H}), 6.53(\mathrm{~d}, 1 \mathrm{H}, J=2.5 \mathrm{~Hz}), 6.62(\mathrm{dd}, 1 \mathrm{H}, J=8.5$ and $2.5 \mathrm{~Hz}), 7.00(\mathrm{~d}, 2 \mathrm{H}, J=$ 8.5 Hz) and 7.28-7.45 $(\mathrm{m}, 12 \mathrm{H}) ;{ }^{13} \mathrm{C}$ NMR (DMSO- $\left.d_{6}\right) \delta 21.29,61.27,69.87,69.92$, $71.39,71.85,72.00,74.98,102.31,108.94,113.94,115.34,128.37,128.45,128.56$, $129.13,129.30,130.16,131.89,137.64,155.00,159.06,160.49,169.99$; mass spectrum (FAB), $m / z 540.2150(\mathrm{M}+\mathrm{H})^{+}\left(\mathrm{C}_{31} \mathrm{H}_{29} \mathrm{O}_{4}\right.$ requires 540.2148).

(2S,3R)-2-(4-Benzoxyphenyl)-7-benzoxy-4-(2-hydroxyethoxy)chroman-3-yl Acetate. Identical NMR spectral data as enantiomer. $[\alpha]^{23}{ }_{\mathrm{D}}+28.5\left(c 1.3, \mathrm{CHCl}_{3}\right)$. 
<smiles>CCCCCC(=O)c1c(OC)cc(OC)cc1OC</smiles>

1-(2,4,6-Trimethoxyphenyl)dodecan-1-one (8). To a solution containing $3.30 \mathrm{~g}$ (19.6 mmol) of 1,3,5-trimethoxybenzene in $100 \mathrm{~mL}$ anhydrous diethyl ether was added $34.4 \mathrm{~g}$ (37.3 $\mathrm{mL}, 157 \mathrm{mmol})$ of lauroyl chloride. The reaction mixture was stirred at $0{ }^{\circ} \mathrm{C}$ for 10 min, then $4 \mathrm{~mL}$ of conc. $\mathrm{H}_{2} \mathrm{SO}_{4}$ was added dropwise. The reaction mixture was warmed to room temperature overnight, poured into ice water and extracted with three $200-\mathrm{mL}$ portions of ethyl acetate. The combined organic layer was washed with two $150-\mathrm{mL}$ portions of $2.0 \mathrm{M} \mathrm{NaOH}, 100 \mathrm{~mL}$ of brine, dried $\left(\mathrm{MgSO}_{4}\right)$, and concentrated under diminished pressure. The resulting residue was purified by flash chromatography on a silica gel column $(28 \times 4 \mathrm{~cm})$. Elution with 7:1 hexanes-ethyl acetate gave 8 as a colorless solid: yield $4.95 \mathrm{~g}$ (72\%); silica gel TLC $R_{f} 0.50$ (3:1 hexanes-ethyl acetate); ${ }^{1} \mathrm{H} \mathrm{NMR}\left(\mathrm{CDCl}_{3}\right) \delta 0.87(\mathrm{t}, 3 \mathrm{H}, J=7.0 \mathrm{~Hz}), 1.25(\mathrm{~m}, 18 \mathrm{H}), 2.71(\mathrm{t}, 2 \mathrm{H}, J=7.5 \mathrm{~Hz}), 3.76$ (s, 6H), $3.81(\mathrm{~s}, 3 \mathrm{H})$ and $6.08(\mathrm{~s}, 2 \mathrm{H}) ;{ }^{13} \mathrm{C} \mathrm{NMR}\left(\mathrm{CDCl}_{3}\right) \delta 14.48,23.04,24.27,29.55-$ 29.99 (alkyl chain), 32.25, 45.29, 55.69, 56.05, 90.77, 105.86, 113.95, 158.15, 162.16 and 189.49; mass spectrum (FAB), $m / z 351.2534(\mathrm{M}+\mathrm{H})^{+}\left(\mathrm{C}_{21} \mathrm{H}_{35} \mathrm{O}_{4}\right.$ requires 351.2535). Note: The NMR spectra of intermediates after the Lewis-acid promoted condensation reaction are complicated by the existence of atropisomerism which often leads to peak doubling.

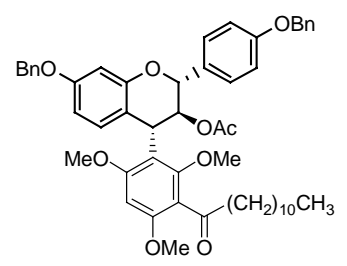




\section{(2R,3S,4S)-7-(Benzoxy)-2-(4-(benzoxy)phenyl)-4-(3-dodecanoyl-2,4,6-}

trimethoxyphenyl)chroman-3-yl Acetate (10). To a solution containing $0.40 \mathrm{~g}(0.74$

mmol) of $\mathbf{6}$ and $1.30 \mathrm{~g}(3.70 \mathrm{mmol})$ of $\mathbf{8}$ in $5 \mathrm{~mL}$ of anhydrous methylene chloride at $0{ }^{\circ} \mathrm{C}$ under $\mathrm{N}_{2}$ was added dropwise $0.33 \mathrm{~g}(1.48 \mathrm{mmol})$ of TMSOTf. The reaction mixture was stirred at $0{ }^{\circ} \mathrm{C}$ until the starting material had disappeared as judged by TLC (approximately $1 \mathrm{~h}$ ). The reaction mixture was then treated with phosphate buffer, $\mathrm{pH} 7$, and diluted with $25 \mathrm{~mL}$ of water. The separated aqueous layer was extracted with three 40-mL portions of methylene chloride. The combined organic layer was washed with two 25-mL portions of brine, dried $\left(\mathrm{MgSO}_{4}\right)$ and concentrated under diminished pressure. The resulting residue was purified by flash chromatography on a silica gel column ( $29 \mathrm{x}$ $3 \mathrm{~cm}$ ). Elution with 4:1 hexanes-ethyl acetate gave $\mathbf{1 0}$ the desired 2,4-cis product as a colorless oil: yield $0.49 \mathrm{~g}(75 \%)$ along with $0.15 \mathrm{~g}(25 \%)$ of the trans isomer; silica gel TLC $R_{f} 0.39$ (3:1 hexanes-ethyl acetate); $[\alpha]^{21}{ }_{\mathrm{D}}-44.4\left(c 1.0, \mathrm{CHCl}_{3}\right) ;{ }^{1} \mathrm{H} \mathrm{NMR}\left(\mathrm{CDCl}_{3}\right)$ $\delta 0.88(\mathrm{t}, 3 \mathrm{H}, J=6.5 \mathrm{~Hz}), 1.26(\mathrm{~m}, 16 \mathrm{H}), 1.64(\mathrm{~s}, 3 \mathrm{H}) ; 1.65(\mathrm{~m}, 2 \mathrm{H}), 2.35(\mathrm{t}, 2 \mathrm{H}, J=5.0$ Hz), $2.77(\mathrm{~m}, 2 \mathrm{H}), 3.63(\mathrm{~s}, 3 \mathrm{H}), 3.79(\mathrm{~s}, 6 \mathrm{H}), 4.67(\mathrm{~d}, 1 \mathrm{H}, J=9.5 \mathrm{~Hz}), 4.94(\mathrm{~d}, 1 \mathrm{H}, J=$ $10.0 \mathrm{~Hz}), 5.00(\mathrm{~s}, 2 \mathrm{H}), 5.08(\mathrm{~s}, 2 \mathrm{H}), 6.01(\mathrm{dd}, 1 \mathrm{H}, J=10.0$ and $9.5 \mathrm{~Hz}), 6.22(\mathrm{~s}, 1 \mathrm{H}), 6.46$ $(\mathrm{dd}, 1 \mathrm{H}, J=2.5$ and $2.0 \mathrm{~Hz}), 6.57(\mathrm{~d}, 1 \mathrm{H}, J=2.0 \mathrm{~Hz}), 6.64(\mathrm{~d}, 1 \mathrm{H}, J=8.5 \mathrm{~Hz}), 6.99(\mathrm{~d}$,

$2 \mathrm{H}, J=8.5 \mathrm{~Hz})$ and 7.32-7.44 (m, 10H); ${ }^{13} \mathrm{C} \mathrm{NMR}\left(\mathrm{CDCl}_{3}\right) \delta 14.40,20.71,22.96,24.25$, 24.99, 29.35-29.93 (alkyl chain), 32.20, 34.28, 39.50, 45.36, 55.86, 56.34, 64.30, 70.23, $70.26,80.90,93.46,102.55,109.21,114.22,114.99,117.87,118.53,127.69,127.74$, $128.11,128.20,128.37,128.76,128.81,129.29,130.68,137.20,137.35,155.23,157.12$, $158.05,158.37,159.32,160.78,169.14,179.54$ and 205.45; mass spectrum (FAB), $m / z$ $827.4157(\mathrm{M}-\mathrm{H})^{+}\left(\mathrm{C}_{52} \mathrm{H}_{59} \mathrm{O}_{9}\right.$ requires 827.4159). 
$(2 S, 3 R, 4 R)-7-(B e n z o x y)-2-(4-(b e n z o x y) p h e n y l)-4-(3-d o d e c a n o y l-2,4,6-$

trimethoxyphenyl)chroman-3-yl Acetate. Identical NMR spectral data as enantiomer. $[\alpha]^{23}{ }_{D}+40.5\left(c 0.9, \mathrm{CHCl}_{3}\right)$.

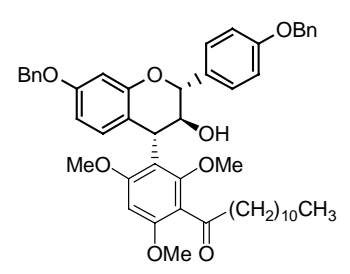

$(2 R, 3 S, 4 S)$-2-(4-Benzoxyphenyl)-7-benzoxy-4-(2,4,6-trimethoxy-3-

(dodecanoyl)phenyl)chroman-3-ol (11). To a solution containing $1.26 \mathrm{~g}(1.52 \mathrm{mmol})$ of 10 in $20 \mathrm{~mL}$ of 1:1 THF-MeOH was added $0.43 \mathrm{~g}$ (3.04 mmol) of $\mathrm{K}_{2} \mathrm{CO}_{3}$. The reaction mixture was stirred at room temperature for $48 \mathrm{~h}$ under $\mathrm{N}_{2}$ then poured into $200 \mathrm{~mL}$ water and extracted with three $250-\mathrm{mL}$ portions of ethyl acetate. The combined organic layer was washed with two $100-\mathrm{mL}$ portions of water and brine, dried $\left(\mathrm{MgSO}_{4}\right)$ and concentrated under diminished pressure. The resulting residue was purified by flash chromatography on silica gel column $(28 \times 4 \mathrm{~cm})$. Elution with 3:1 hexanes-ethyl acetate gave $\mathbf{1 1}$ as a colorless viscous oil: yield $1.10 \mathrm{~g}$ (92\%); silica gel TLC $R_{f} 0.47$ (2:1 hexanes-ethyl acetate); $[\alpha]_{D}^{22}-63.5\left(c 1.1, \mathrm{CHCl}_{3}\right)$; the product was isolated as an inseparable mixture of atropisomers; ${ }^{1} \mathrm{H} \mathrm{NMR}\left(\mathrm{CDCl}_{3}\right) \delta 0.94(\mathrm{t}, 3 \mathrm{H}, J=7.0 \mathrm{~Hz}), 1.30$ $(\mathrm{m}, 16 \mathrm{H}), 1.71(\mathrm{~m}, 2 \mathrm{H}), 1.68(\mathrm{t}, 2 \mathrm{H}, J=7.0 \mathrm{~Hz}), 2.96(\mathrm{br} \mathrm{s}, 1 \mathrm{H}) 3.55(\mathrm{~s}, 2 \mathrm{H}), 3.83(\mathrm{~s}$, 3H), $3.86(\mathrm{~s}, 3 \mathrm{H}), 3.88(\mathrm{~s}, 3 \mathrm{H}), 3.95(\mathrm{~s}, 1 \mathrm{H}), 4.50(\mathrm{t}, 0.6 \mathrm{H}, J=9.5 \mathrm{~Hz}), 4.63(\mathrm{~m}, 1 \mathrm{H}), 4.78$ $(\mathrm{d}, 0.4 \mathrm{H}, J=9.5 \mathrm{~Hz}), 4.85(\mathrm{~d}, 1 \mathrm{H}, J=9.5 \mathrm{~Hz}), 5.03(\mathrm{~s}, 2 \mathrm{H}), 5.12(\mathrm{~s}, 2 \mathrm{H}), 6.30(\mathrm{~s}, 0.6 \mathrm{H})$ $6.39(\mathrm{~s}, 0.4 \mathrm{H}), 6.50(\mathrm{dd}, 1 \mathrm{H}, J=2.5$ and $2.0 \mathrm{~Hz}), 6.60(\mathrm{~d}, 1 \mathrm{H}, J=2.0 \mathrm{~Hz}), 6.67(\mathrm{dd}, 1 \mathrm{H}, J$ $=8.5$ and $8.0 \mathrm{~Hz}), 7.07(\mathrm{~d}, 2 \mathrm{H}, J=8.5 \mathrm{~Hz}), 7.32$ and $7.30(\mathrm{~m}, 10 \mathrm{H}) ;{ }^{13} \mathrm{C} \mathrm{NMR}\left(\mathrm{CDCl}_{3}\right) \delta$ 14.45, 22.99, 24.14, 29.47-29.95 (alkyl chain), 32.21, 40.25, 41.11, 45.31, 56.02, 56.16, 
$56.70,61.88,70.25,70.43,71.47 .82 .94,91.29,93.51,102.35,102.35,102.68,108.97$,

109.21, 115.31, 115.82, 116.43, 118.64, 119.08, 119.30, 127.71, 128.14, 128.29, 128.76,

$128.89,129.38,130.61,130.74,137.15,137.36,155.51,155.71,156.82,157.14,157.74$,

$158.14,158.34,159.43,160.18,161.03$ and 205.64 ; mass spectrum (FAB), $m / z .787 .4213$

$(\mathrm{M}+\mathrm{H})^{+}\left(\mathrm{C}_{50} \mathrm{H}_{59} \mathrm{O}_{8}\right.$ requires 787.4210).

$(2 R, 3 S, 4 S)$-2-(4-Benzoxyphenyl)-7-benzoxy-4-(2,4,6-trimethoxy-3-

(dodecanoyl)phenyl)chroman-3-ol. Identical NMR spectral data as enantiomer. $[\alpha]^{19}$ $+65.1\left(c 1.0, \mathrm{CHCl}_{3}\right)$

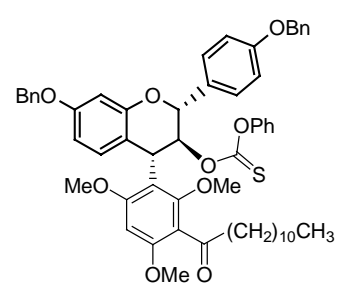

$(2 R, 3 S, 4 S)$-2-(4-Benzoxyphenyl)-7-benzoxy-4-(2,4,6-trimethoxy-3-

(dodecanoyl)phenyl)chroman-3-O-phenylcarbonothioate. To a solution containing

$0.60 \mathrm{~g}(0.76 \mathrm{mmol})$ of $\mathbf{1 1}$ in $15 \mathrm{~mL}$ of anhydrous acetonitrile was added $0.56 \mathrm{~g}$ (4.57

mmol) of 4- $N, N$-dimethylaminopyridine followed by $0.54 \mathrm{~g}(0.41 \mathrm{~mL}, 3.05 \mathrm{mmol})$ of phenyl chlorothionoformate and the reaction mixture was heated to $50{ }^{\circ} \mathrm{C}$ and maintained at this temperature under $\mathrm{N}_{2}$ for $24 \mathrm{~h}$. The cooled reaction mixture was then diluted with $150 \mathrm{~mL}$ of water. The separated aqueous layer was extracted with three $25-\mathrm{mL}$ portions of ethyl acetate. The combined organic layer was washed with $100 \mathrm{~mL}$ of brine, dried $\left(\mathrm{MgSO}_{4}\right)$ and concentrated under diminished pressure. The residue was purified by flash chromatography on a silica gel column $(25 \times 4 \mathrm{~cm})$. Elution with 4:1 hexanes-ethyl acetate gave the product as a colorless oil: yield $0.53 \mathrm{~g} \mathrm{(76 \% );} \mathrm{silica} \mathrm{gel} \mathrm{TLC} R_{f} 0.40$ (3:1 hexanes-ethyl acetate); $[\alpha]^{21}-42.7\left(c 1.7, \mathrm{CHCl}_{3}\right)$; product was isolated as an 
inseparable mixture of atropisomers; ${ }^{1} \mathrm{H} \mathrm{NMR}\left(\mathrm{CDCl}_{3}\right) \delta 0.93(\mathrm{t}, 3 \mathrm{H}, J=7.0 \mathrm{~Hz}), 1.34$ (m, 16H), $1.76(\mathrm{t}, 2 \mathrm{H}, J=7.0 \mathrm{~Hz}), 2.89(\mathrm{~m}, 2 \mathrm{H}), 3.65(\mathrm{~s}, 3 \mathrm{H}), 3.81(\mathrm{~s}, 2 \mathrm{H}), 3.86(\mathrm{~s}, 1 \mathrm{H})$, $3.91(\mathrm{~s}, 2 \mathrm{H}), 3.97(\mathrm{~s}, 1 \mathrm{H}), 4.96(\mathrm{~d}, 1 \mathrm{H}, J=9.5 \mathrm{~Hz}), 5.05(\mathrm{~s}, 2 \mathrm{H}), 5.11(\mathrm{dd}, 1 \mathrm{H}, J=5.0$ and $4.5 \mathrm{~Hz}), 5.14(\mathrm{~s}, 2 \mathrm{H}), 6.22(\mathrm{~s}, 0.7 \mathrm{H}), 6.36(\mathrm{~s}, 0.3 \mathrm{H}), 6.55(\mathrm{dd}, 1 \mathrm{H}, J=2.5$ and $2.0 \mathrm{~Hz})$, 6.55-6.77 (m, 5H), $7.08(\mathrm{~d}, 2 \mathrm{H}, J=8.5 \mathrm{~Hz})$ and 7.16-7.56 (m, 15H); ${ }^{13} \mathrm{C} \mathrm{NMR}\left(\mathrm{CDCl}_{3}\right) \delta$ 14.46, 23.00, 24.24, 29.41, 29.96 (alkyl chain), 32.21, 39.16, 45.49, 55.97, 56.29, 64.43, $70.29,80.26,80.35,92.94,102.53,109.51,113.47,114.95,117.58,118.50,121.91$, $126.61,127.72,128.21,128.46,128.79,128.83,128.90,129.13,129.28,129.36,129.49$, $129.56,129.75,129.80,137.16,137.25,153.43,155.05,157.37,158.14,158.35,159.51$, 160.73, 194.04 and 205.52. Note: product was relatively unstable and was used immediately in the next reaction.

(2S,3R,4R)-2-(4-Benzoxyphenyl)-7-benzoxy-4-(2,4,6-trimethoxy-3(dodecanoyl)phenyl)chroman-3- $O$-phenylcarbonothioate. Identical NMR spectral data as enantiomer. $[\alpha]^{19}{ }_{D}+40.3\left(c 1.5, \mathrm{CHCl}_{3}\right)$

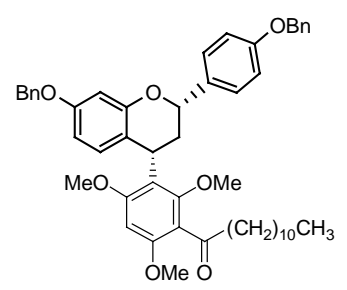

\section{(2S,4S)-2-(4-Benzoxyphenyl)-7-benzoxy-4-(2,4,6-trimethoxy-3-}

(dodecanoyl)phenyl)chroman (12). To a solution containing $0.17 \mathrm{~g}(0.18 \mathrm{mmol})$ of aforementioned carbonothioate in $10 \mathrm{~mL}$ of anhydrous toluene was added $0.27 \mathrm{~g}(0.91$ mmol) of $\mathrm{SnBu}_{3} \mathrm{H}$ followed by cat. AIBN $(\sim 10 \mathrm{mg})$. The reaction mixture was heated to a gentle reflux under $\mathrm{N}_{2}$ for $6 \mathrm{~h}$ then cooled to room temperature. The excess solvent was then removed under diminished pressure and the crude residue was applied directly to a 
silica column for purification. Flash chromatography on silica gel column $(28 \times 3 \mathrm{~cm})$, elution with 5:1 hexanes-ethyl acetate provided $\mathbf{1 2}$ as a colorless foam: yield $0.13 \mathrm{~g}$ (95\%); silica gel TLC $R_{f} 0.28$ (4:1 hexanes-ethyl acetate); $[\alpha]^{21}{ }_{\mathrm{D}}-49.5\left(c 1.3, \mathrm{CHCl}_{3}\right)$; the product was isolated as an inseparable mixture of atropisomers; ${ }^{1} \mathrm{H} \mathrm{NMR}\left(\mathrm{CDCl}_{3}\right) \delta$ $0.92(\mathrm{t}, 3 \mathrm{H}, J=6.9 \mathrm{~Hz}), 1.31(\mathrm{~m}, 16 \mathrm{H}), 1.69(\mathrm{~m}, 2 \mathrm{H}), 2.12(\mathrm{dd}, 1 \mathrm{H}, J=13.2$ and $6.0 \mathrm{~Hz})$, $2.84(\mathrm{t}, 1 \mathrm{H}, J=7.2 \mathrm{~Hz}), 2.96(\mathrm{~s}, 1 \mathrm{H}), 3.53(\mathrm{~s}, 2 \mathrm{H}), 3.82(\mathrm{~s}, 3 \mathrm{H}), 3.84(\mathrm{~s}, 3 \mathrm{H}), 3.92(\mathrm{~s}, 3 \mathrm{H})$, $4.73(\mathrm{dd}, 0.5 \mathrm{H}, J=11.7$ and $5.7 \mathrm{~Hz}), 4.94(\mathrm{dd}, 0.5 \mathrm{H}, J=11.7$ and $6.0 \mathrm{~Hz}), 5.03(\mathrm{~s}, 2 \mathrm{H})$, $5.11(\mathrm{~s}, 2 \mathrm{H}), 5.18(\mathrm{~d}, 1 \mathrm{H}, J=11.7 \mathrm{~Hz}), 6.27(\mathrm{~s}, 1 \mathrm{H}), 6.34(\mathrm{~s}, 1 \mathrm{H}), 6.45(\mathrm{dd}, 1 \mathrm{H}, J=8.4$ and $2.7 \mathrm{~Hz}), 6.61(\mathrm{t}, 1 \mathrm{H}),(\mathrm{ddd}, 1 \mathrm{H}, J=8.4,4.5$ and $0.9 \mathrm{~Hz}), 7.04(\mathrm{~d}, 2 \mathrm{H}, J=8.7 \mathrm{~Hz})$ and 7.30-7.48 (m, 10H); ${ }^{13} \mathrm{C} \mathrm{NMR}\left(\mathrm{CDCl}_{3}\right) \delta 14.44,17.81,22.98,24.15,27.14,28.14,29.48$, $29.64,29.78,29.93,31.79,32.31,32.96,35.37,45.40,56.08,56.42,61.89,64.37,70.23$, 70.28, 78.84, 79.05, 90.97, 93.58, 102.70, 103.05, 108.33, 108.54, 115.13, 118.17, $118.67,118.94,119.24,119.39,119.98,127.71,127.89,127.98,128.08,128.22,128.76$, $128.85,129.13,134.15,137.49,156.20,156.51,157.11,158.83,159.86,160.61$ and 205.59; mass spectrum (FAB), $m / z 771.4266(\mathrm{M}+\mathrm{H})^{+}\left(\mathrm{C}_{50} \mathrm{H}_{59} \mathrm{O}_{7}\right.$ requires 771.4261$)$. (2R,4R)-2-(4-Benzoxyphenyl)-7-benzoxy-4-(2,4,6-trimethoxy-3(dodecanoyl)phenyl)chroman. Identical NMR spectral data as enantiomer. $[\alpha]^{19}{ }^{+}$ $45.3\left(c 1.3, \mathrm{CHCl}_{3}\right)$

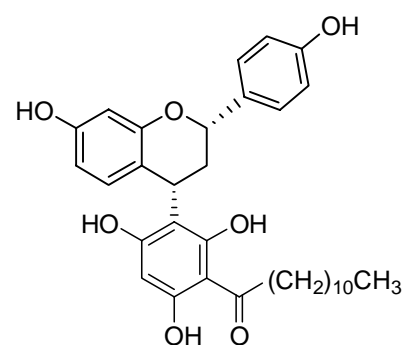


(-)-Myristinin B/C (2a,b). To a solution containing $0.37 \mathrm{~g}(0.48 \mathrm{mmol})$ of $\mathbf{1 2}$ in $2 \mathrm{~mL}$ anhydrous methylene chloride at $-78{ }^{\circ} \mathrm{C}$ was added $7.2 \mathrm{~mL}(7.2 \mathrm{mmol})$ of $1.0 \mathrm{M} \mathrm{BBr}_{3}$ in $\mathrm{CH}_{2} \mathrm{Cl}_{2}$. The solution was allowed warm to room temperature overnight, then cooled to 0 ${ }^{\circ} \mathrm{C}$ and quenched with $10 \mathrm{~mL}$ of water. The separated aqueous layer was extracted with three 50-mL portions of methylene chloride. The combined organic layer was washed with two 10-mL portions of brine, dried $\left(\mathrm{MgSO}_{4}\right)$, and concentrated under diminished pressure. The residue was purified by flash chromatography on a silica gel column $(28 \mathrm{x}$ $3 \mathrm{~cm}$ ). Elution with 1:1:0.05 ethyl acetate-hexanes-methanol gave the product as a mixture of two compounds. Further purification of the crude product was effected by $\mathrm{C}_{18}$ reversed phase HPLC ( $250 \times 21.2 \mathrm{~mm}, 5 \mu \mathrm{m})$. Elution with a linear gradient of $\mathrm{H}_{2} \mathrm{O}$ containing increasing amounts of acetonitrile $(70 \% \rightarrow 100 \%$ over a period of $40 \mathrm{~min}$, at a flow rate of $12 \mathrm{~mL} / \mathrm{min} ; t_{\mathrm{r}} 22.6(\mathbf{1})$ and 23.5 (2a,b) provided both myristinin $\mathrm{B} / \mathrm{C}(\mathbf{2 a}, \mathbf{b})$ and (1) as colorless solids: yield $0.150 \mathrm{~g}(57 \%) ;(\mathbf{2 a , b})[\alpha]^{19} \mathrm{D}-48.3(c 0.4, \mathrm{MeOH}) ;{ }^{1} \mathrm{H}$ NMR (DMSO- $\left.d_{6}\right) \delta 0.84(\mathrm{t}, 3 \mathrm{H}, J=5.8 \mathrm{~Hz}), 1.23(\mathrm{~m}, 16 \mathrm{H}), 1.57(\mathrm{~m}, 2 \mathrm{H}), 1.79(\mathrm{~m}, 1 \mathrm{H})$, $2.61(\mathrm{q}, 0.5 \mathrm{H}, J=12.5 \mathrm{~Hz}), 2.71(\mathrm{q}, 0.5 \mathrm{H}, J=12.5 \mathrm{~Hz}), 2.96(\mathrm{~m}, 1 \mathrm{H}), 3.01(\mathrm{t}, 1 \mathrm{H}, J=8.0$ $\mathrm{Hz}), 4.60(\mathrm{dd}, 0.45 \mathrm{H}, J=12.0$ and $5.5 \mathrm{~Hz}), 4.69(\mathrm{dd}, 0.55 \mathrm{H}, J=11.5$ and $5.5 \mathrm{~Hz}), 5.00$ (dd, 1H, $J=11.0$ and $10.0 \mathrm{~Hz}), 5.91(\mathrm{~s}, 0.55 \mathrm{H}), 6.08(\mathrm{~s}, 0.45 \mathrm{H}), 6.15(\mathrm{~m}, 2 \mathrm{H}), 6.42(\mathrm{~d}$, $1 \mathrm{H}, J=9.0 \mathrm{~Hz}), 6.75(\mathrm{dd}, 2 \mathrm{H}, J=9.0$ and $2.0 \mathrm{~Hz}), 7.24(\mathrm{dd}, 2 \mathrm{H}, J=9.0$ and $2.0 \mathrm{~Hz}), 8.97$ (s, 1H), $9.39(\mathrm{~s}, 1 \mathrm{H}), 10.07(\mathrm{br} \mathrm{s}, 1 \mathrm{H}), 10.55(\mathrm{br} \mathrm{s}, 1 \mathrm{H}), 14.10(\mathrm{~s}, 0.75 \mathrm{H})$ and $14.52(\mathrm{~s}$, $1 \mathrm{H}) ;{ }^{13} \mathrm{C}$ NMR (DMSO- $\left.d_{6}\right) \delta 14.00,22.13,24.56,28.73,28.93,29.02,29.06,29.90$, $29.93,29.96,30.39,30.81,31.32,33.52,33.98,43.20,78.00,78.10,102.60,107.79$, 115.01, 116.94, 127.48, 127.57, 132.12, 155.50, 155.56, 160.31, 160.58, 162.79, 163.12, 
164.16, 164.63 and 205.48; mass spectrum (FAB), $m / z 549.2849(\mathrm{M}+\mathrm{H})^{+}\left(\mathrm{C}_{33} \mathrm{H}_{41} \mathrm{O}_{7}\right.$ requires 549.2847).

(+)-Myristinin B/C. Identical NMR spectral data as enantiomer. $[\alpha]^{23}{ }_{D}+44.6(c 0.6$, $\mathrm{MeOH})$.

Myristinin A (1) isomer (isolated from treatment of 12 with 40 equiv. of $\mathrm{BBr}_{3}$ ). ${ }^{1} \mathrm{H}$ NMR (DMSO- $\left.d_{6}\right) \delta 0.86(\mathrm{t}, 3 \mathrm{H}, J=7.0 \mathrm{~Hz}), 1.25(\mathrm{~m}, 16 \mathrm{H}), 1.56(\mathrm{~m}, 2 \mathrm{H}), 2.07(\mathrm{~m}, 2 \mathrm{H})$, $3.02(\mathrm{~m}, 2 \mathrm{H}), 4.36(\mathrm{~d}, 1 \mathrm{H}, J=3.0 \mathrm{~Hz}), 4.67(\mathrm{dd}, 1 \mathrm{H}, J=12.0$ and $1.5 \mathrm{~Hz}), 5.93(\mathrm{~s}, 1 \mathrm{H})$, $6.08(\mathrm{dd}, 1 \mathrm{H}, J=8.0$ and $2.0 \mathrm{~Hz}), 6.34(\mathrm{~d}, 2 \mathrm{H}, J=2.0 \mathrm{~Hz}), 6.71(\mathrm{~d}, 2 \mathrm{H}, J=9.0 \mathrm{~Hz}), 7.10$ (d, 2H, $J=9.0 \mathrm{~Hz}), 8.98(\mathrm{~s}, 1 \mathrm{H}), 9.32(\mathrm{br} \mathrm{s}, 1 \mathrm{H}), 9.46(\mathrm{br} \mathrm{s}, 1 \mathrm{H}), 10.67$ (br s, 1H) and 14.16 (br s, $1 \mathrm{H}$ ); ${ }^{13} \mathrm{C}$ NMR (DMSO- $d_{6}$ ) $\delta 13.96,22.10,24.42,28.55,28.71,28.88,28.95$, $29.00,31.30,34.40,43.16,73.92,94.17,102.32,102.59,104.24,105.35,115.10,121.44$, $126.63,128.01,128.91,130.58,155.00,156.44,157.32,160.03,161.80$ and 205.75; mass spectrum $(\mathrm{FAB}), \mathrm{m} / z 549.2852(\mathrm{M}+\mathrm{H})^{+}\left(\mathrm{C}_{33} \mathrm{H}_{41} \mathrm{O}_{7}\right.$ requires 549.2847). 


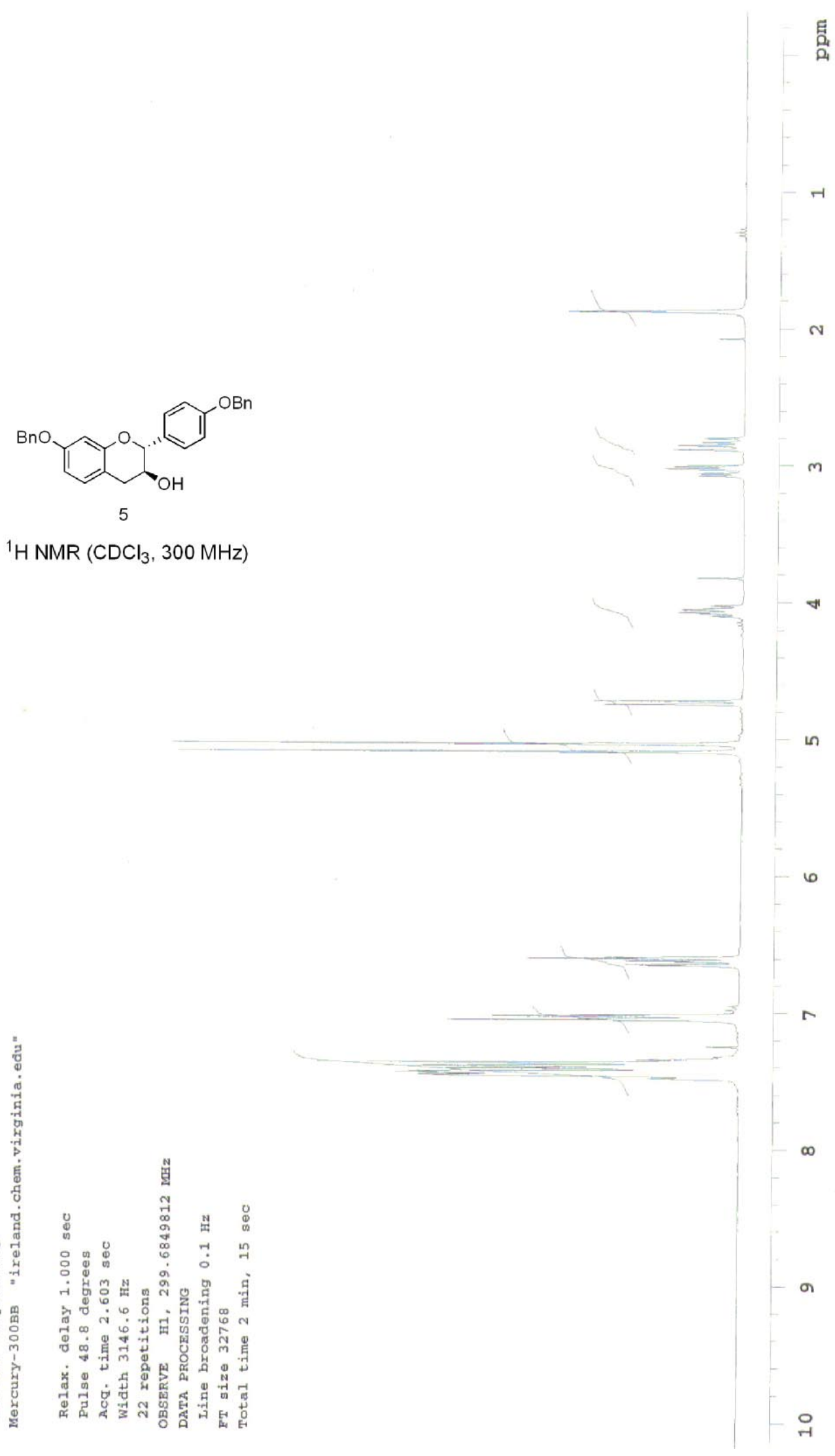




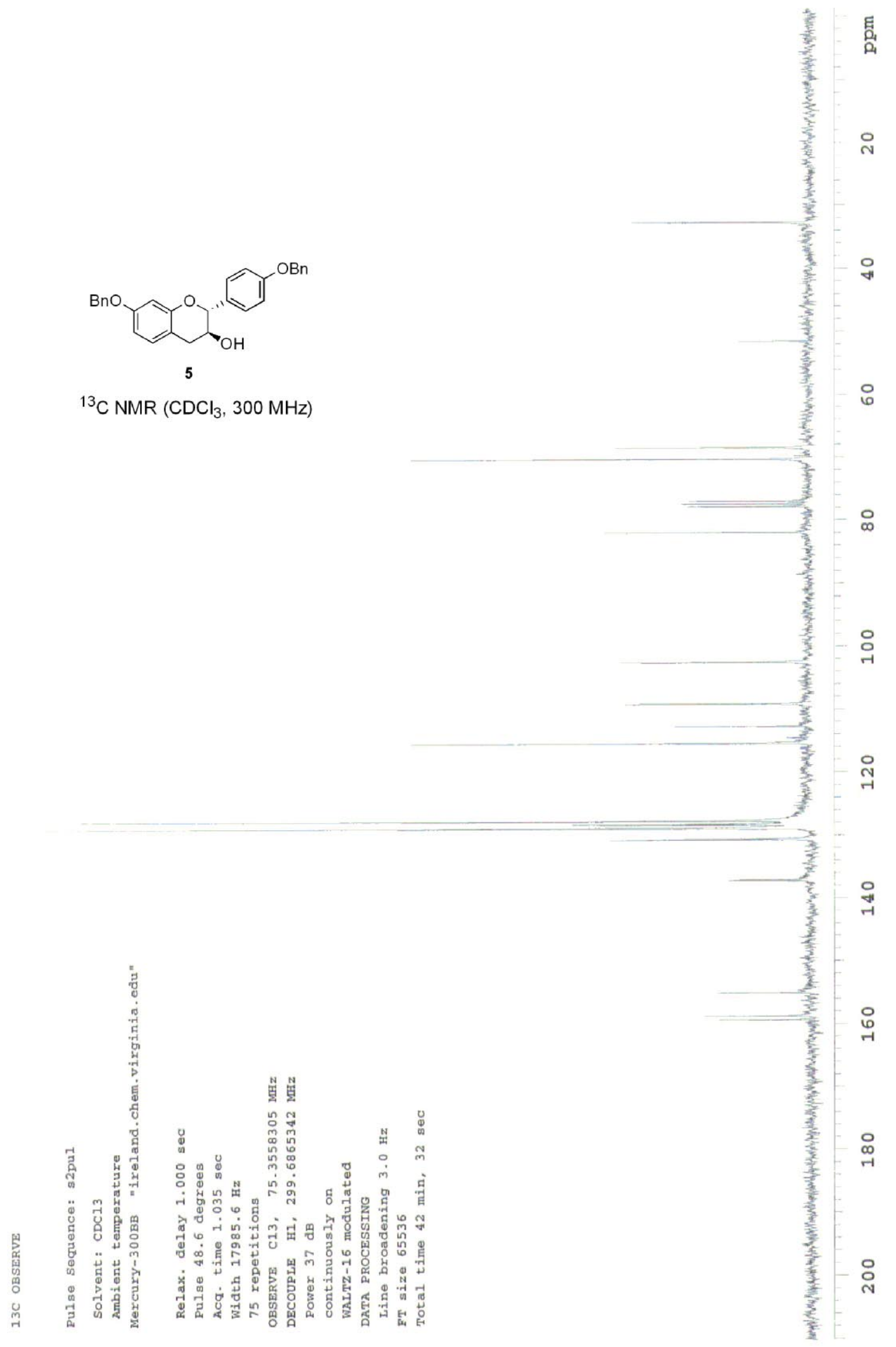




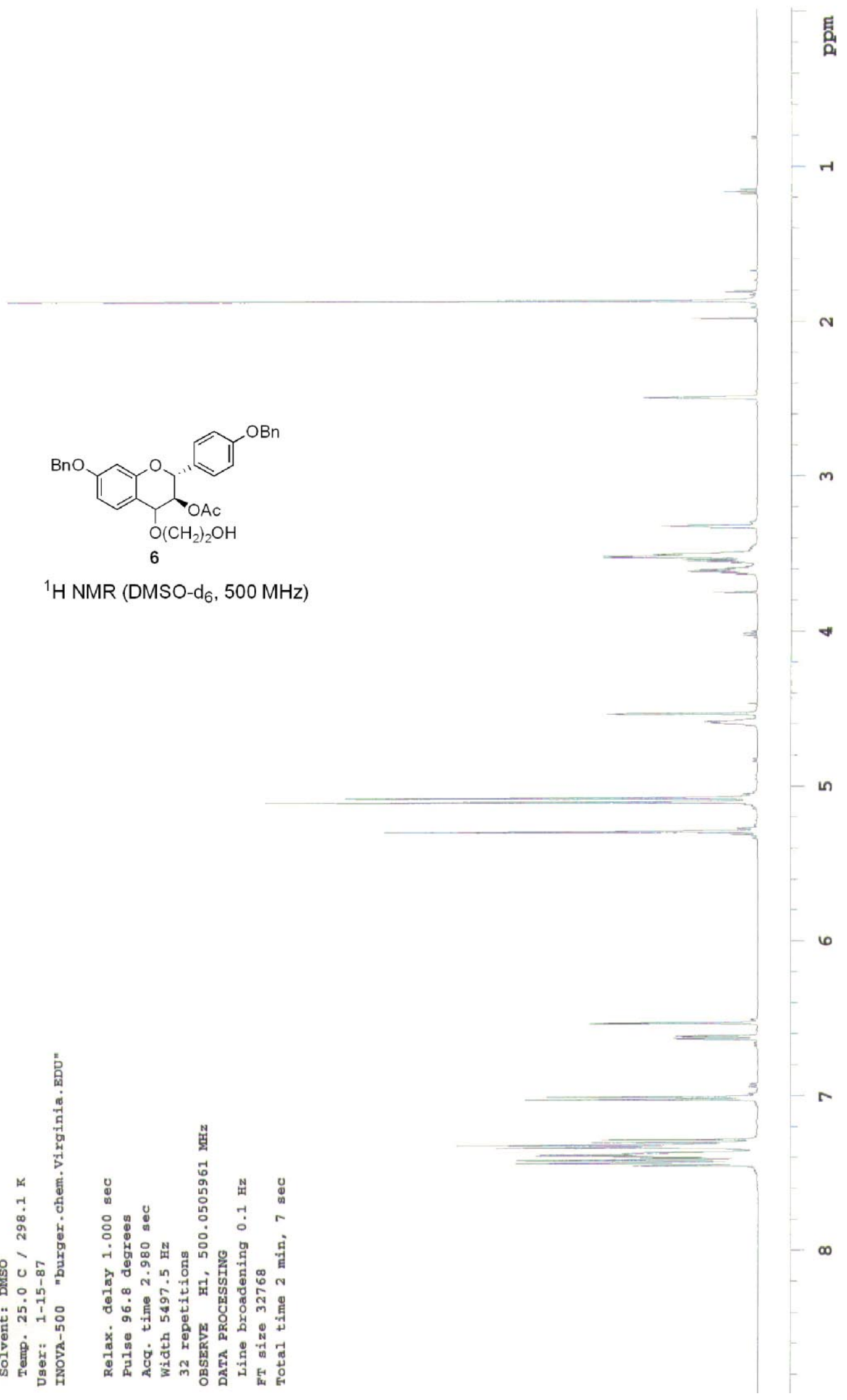




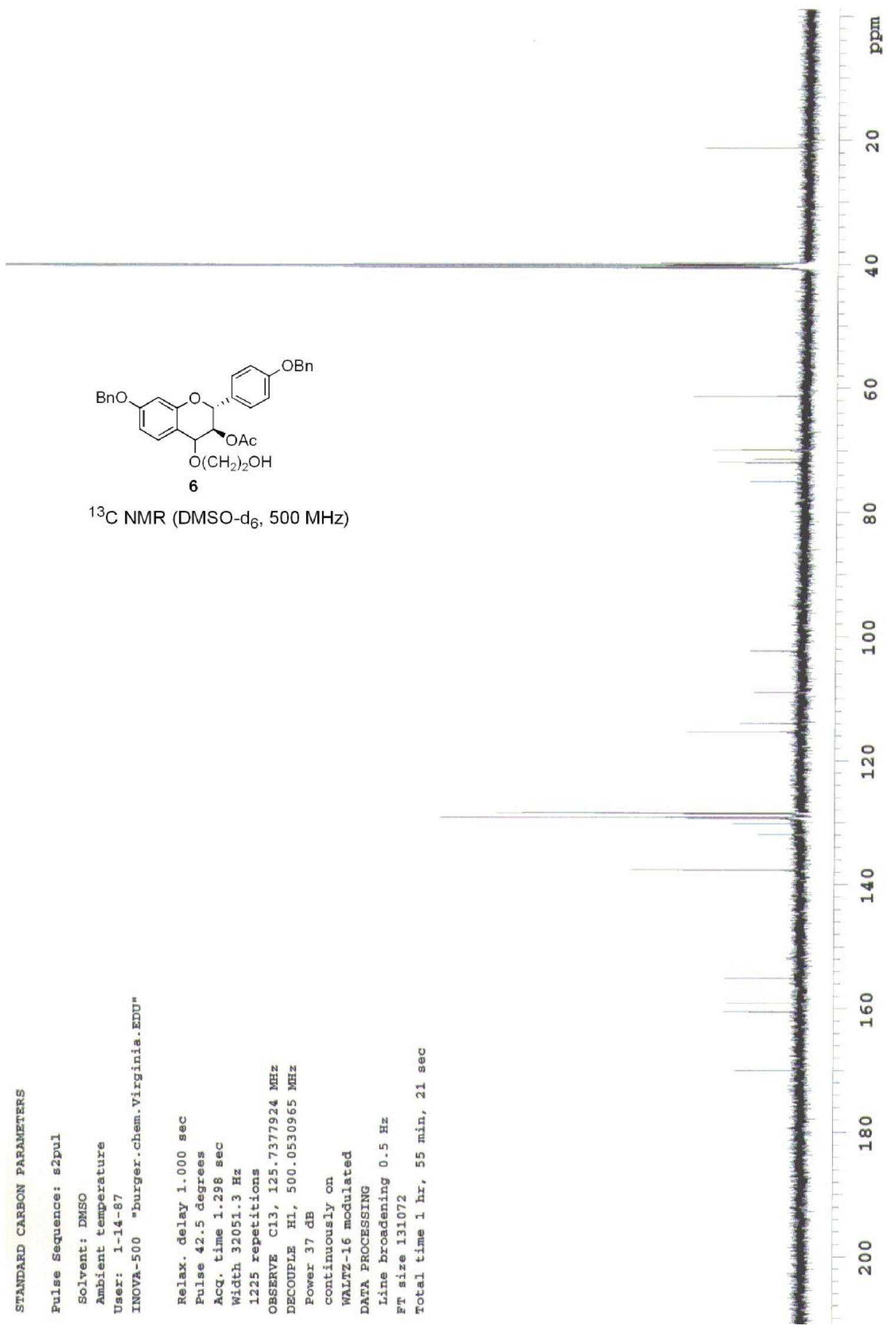




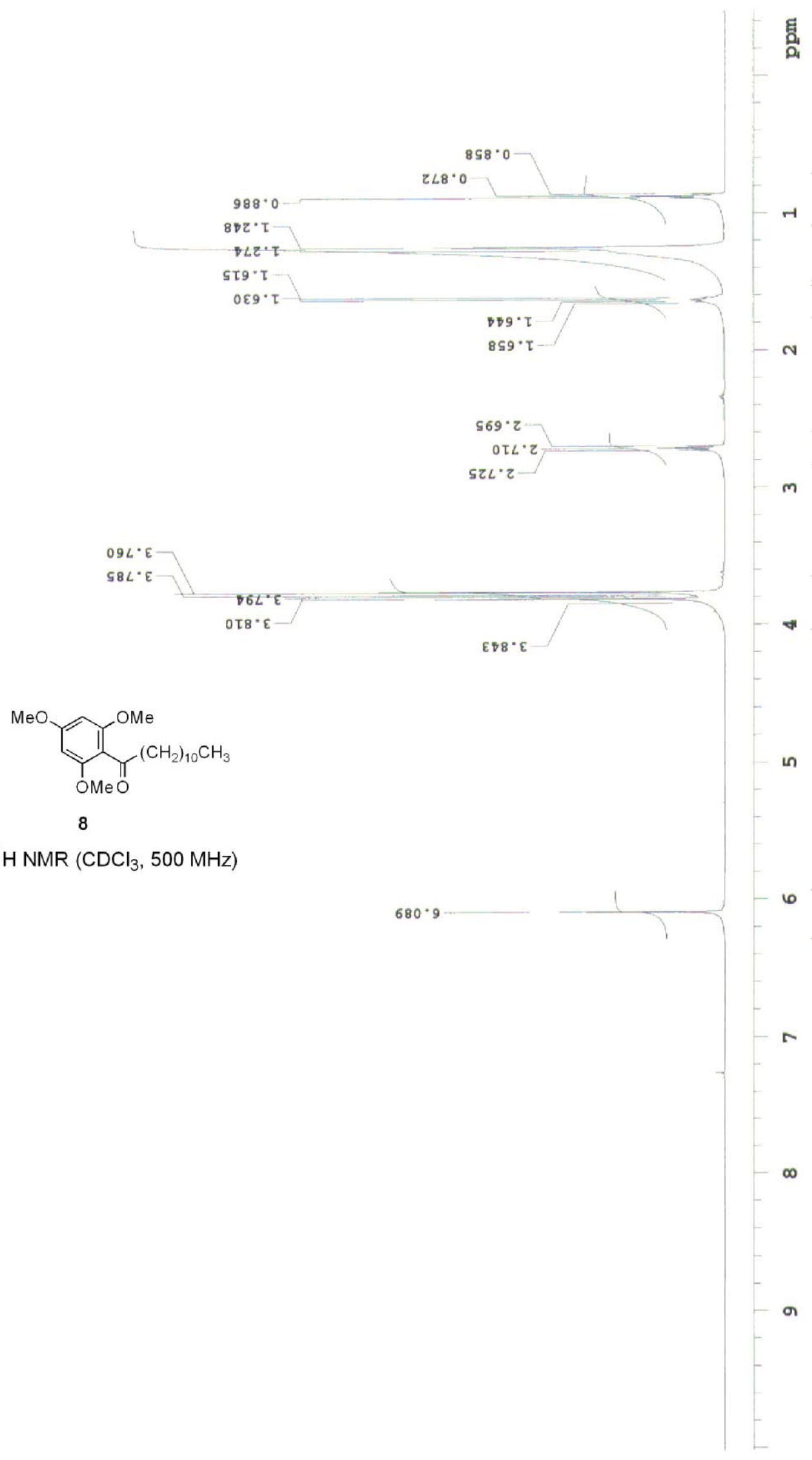




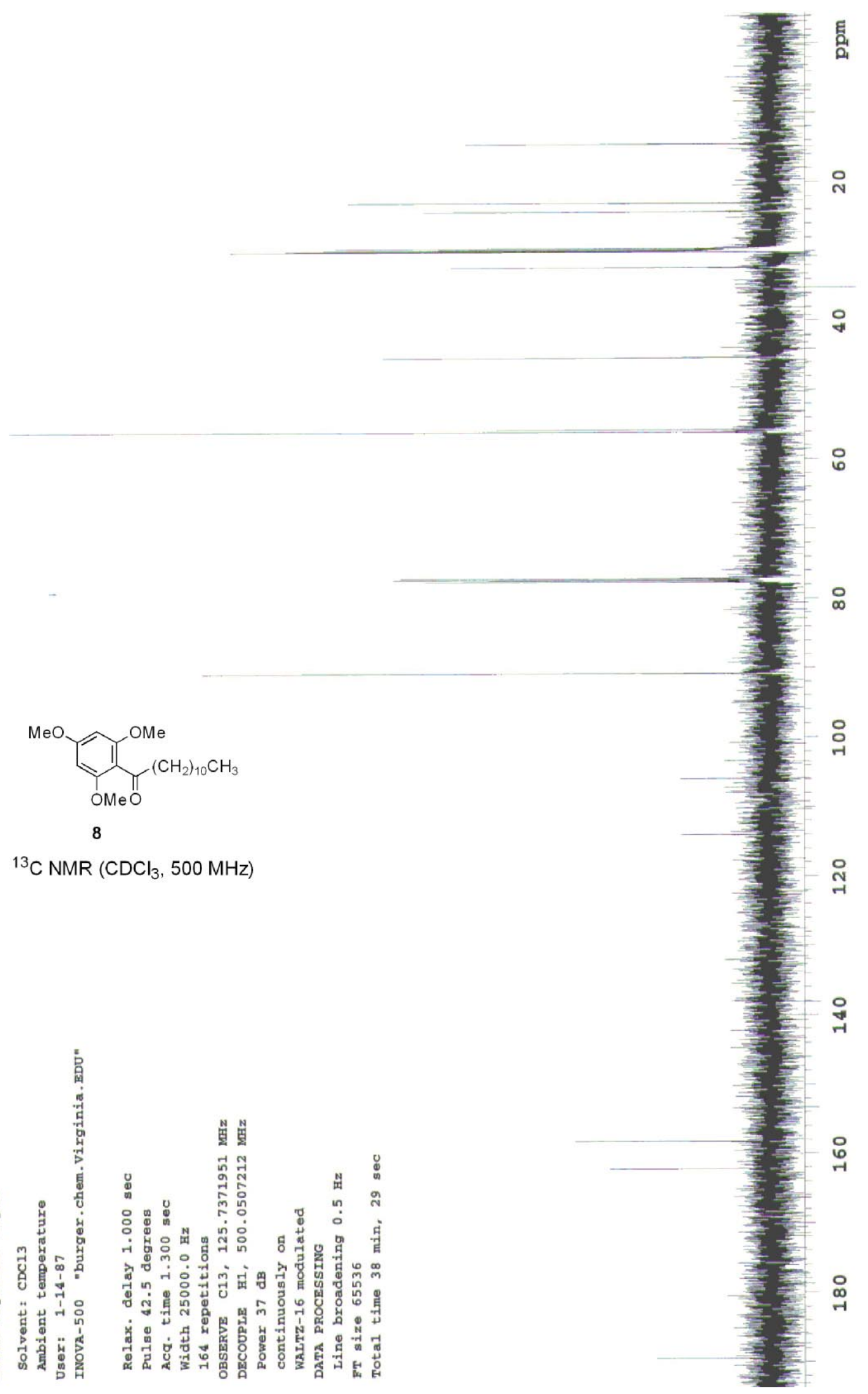




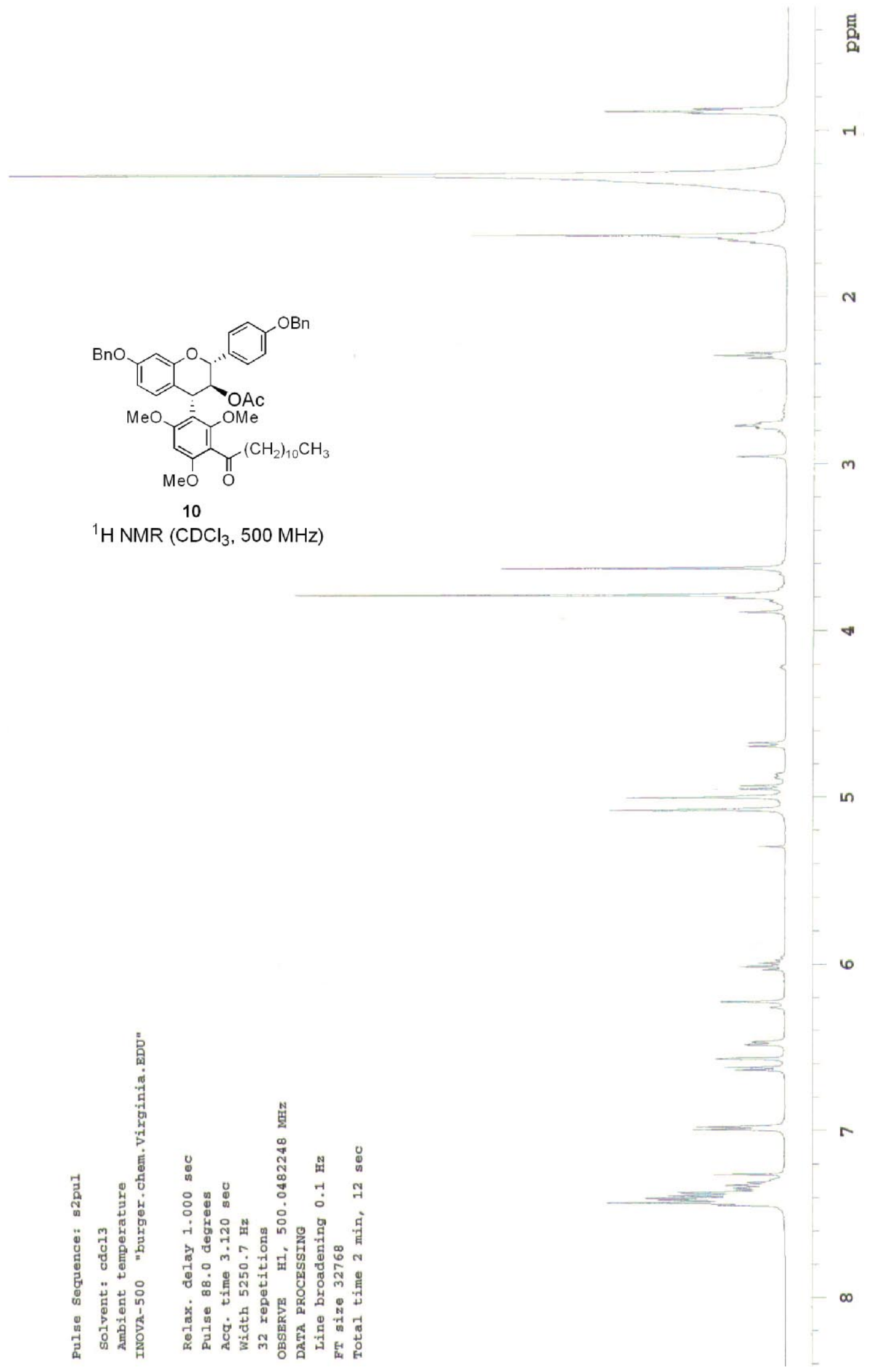




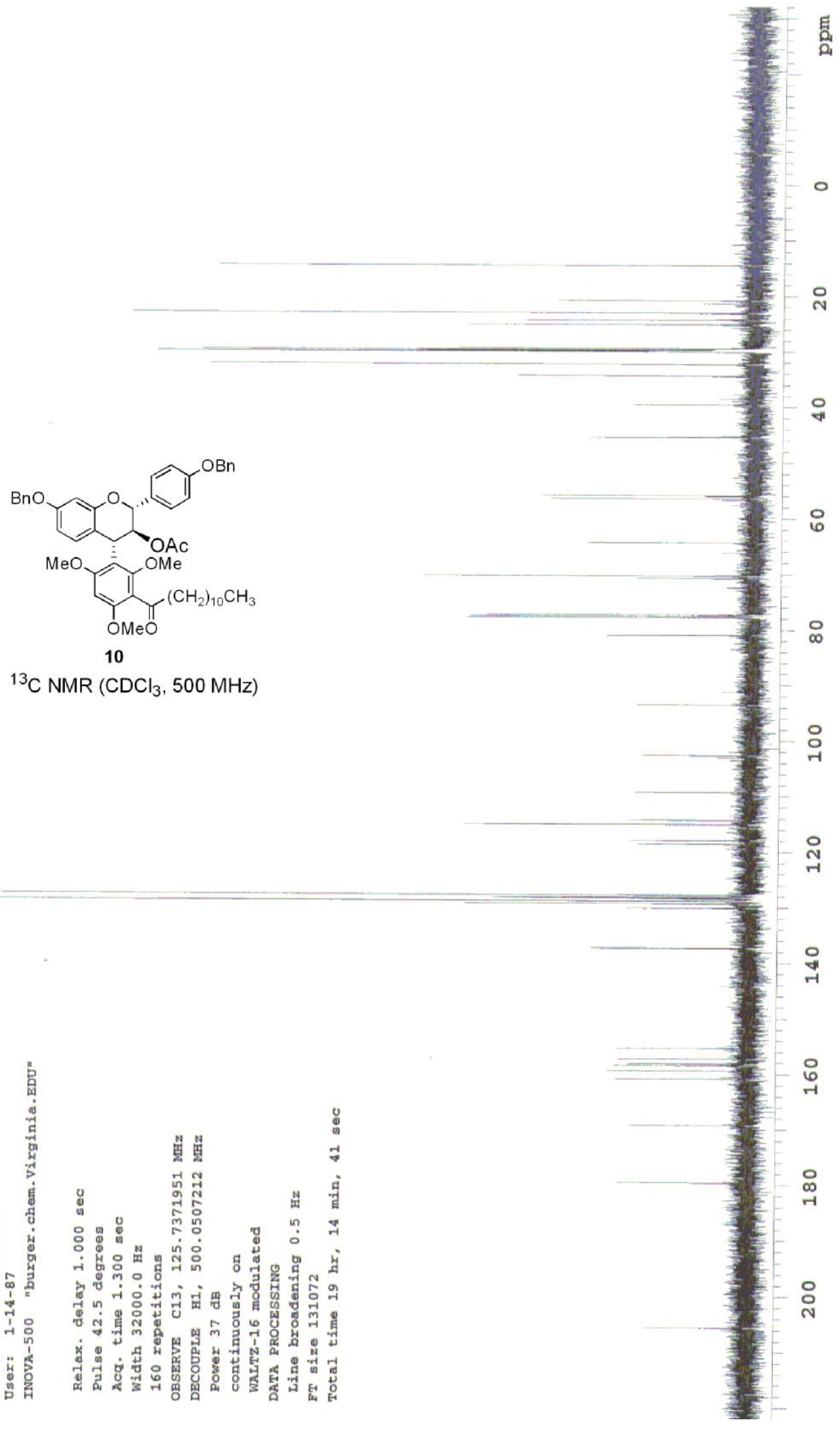




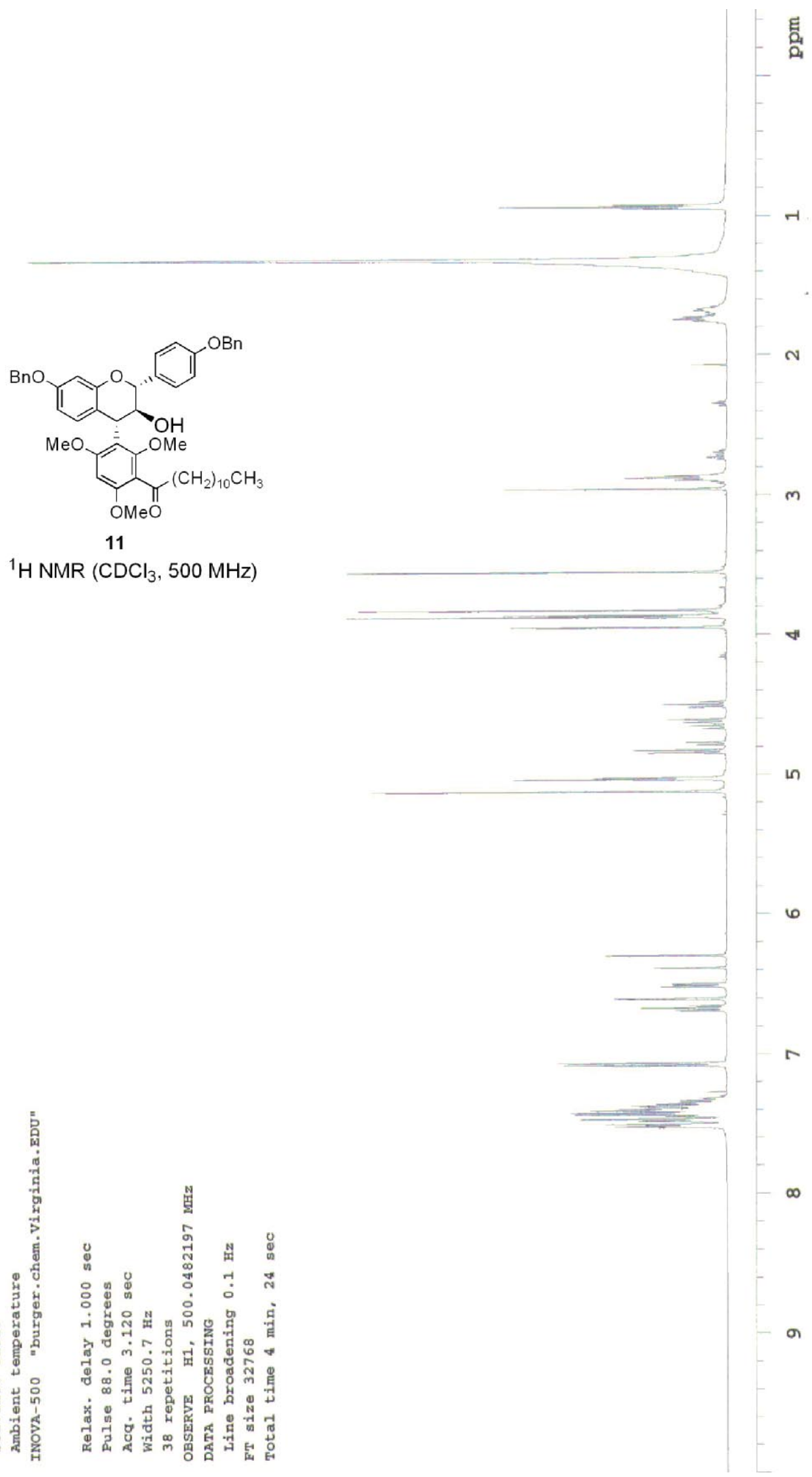




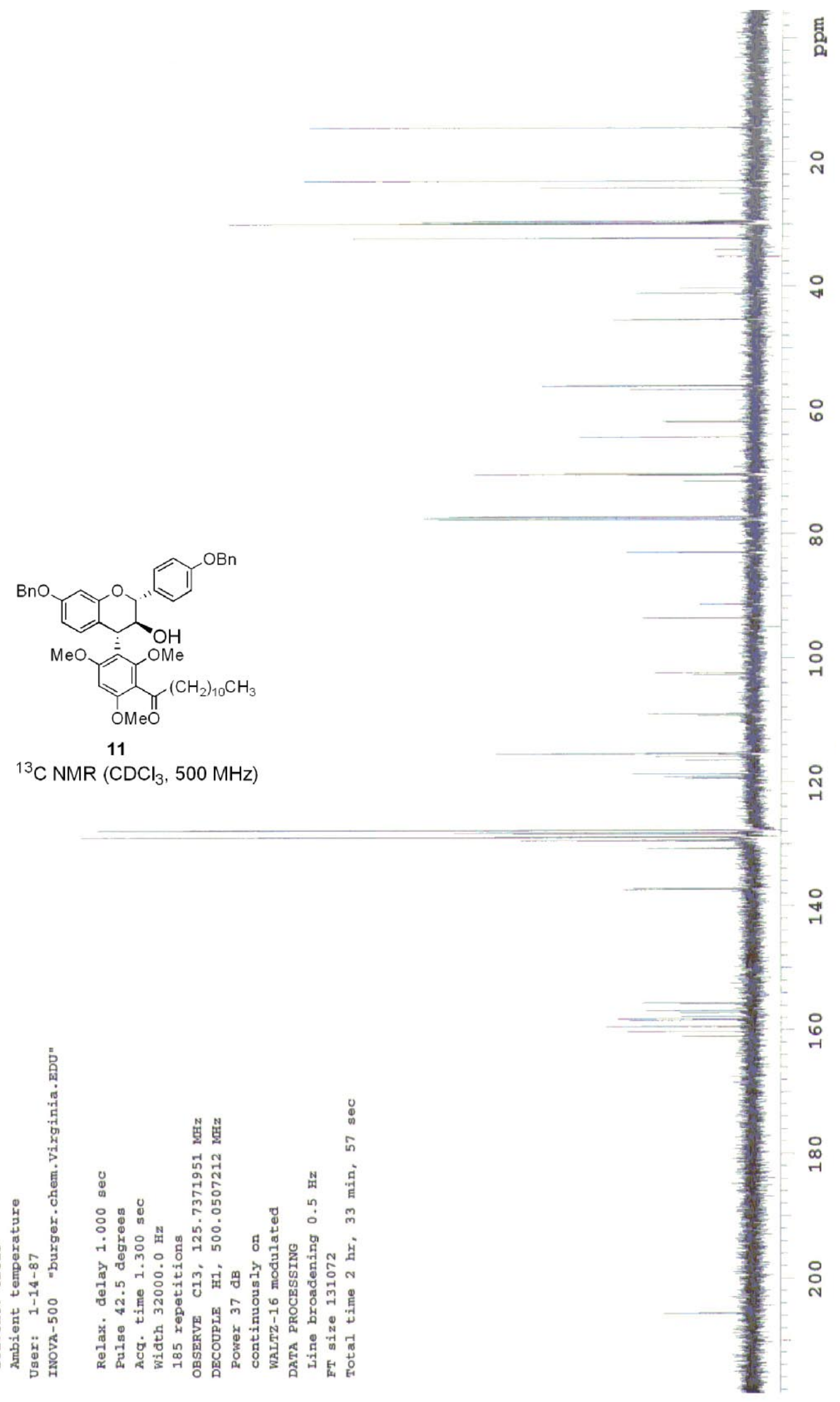




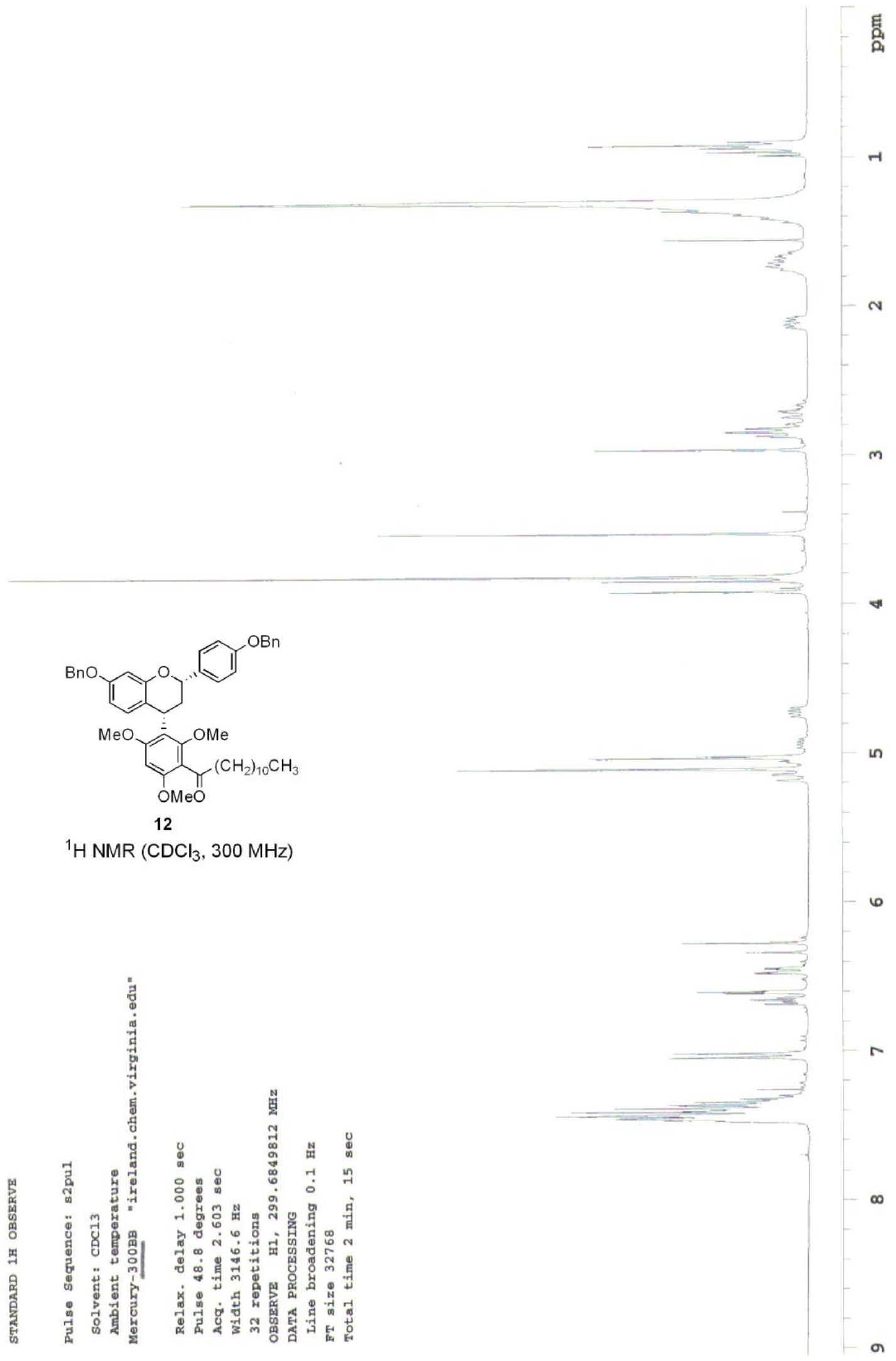




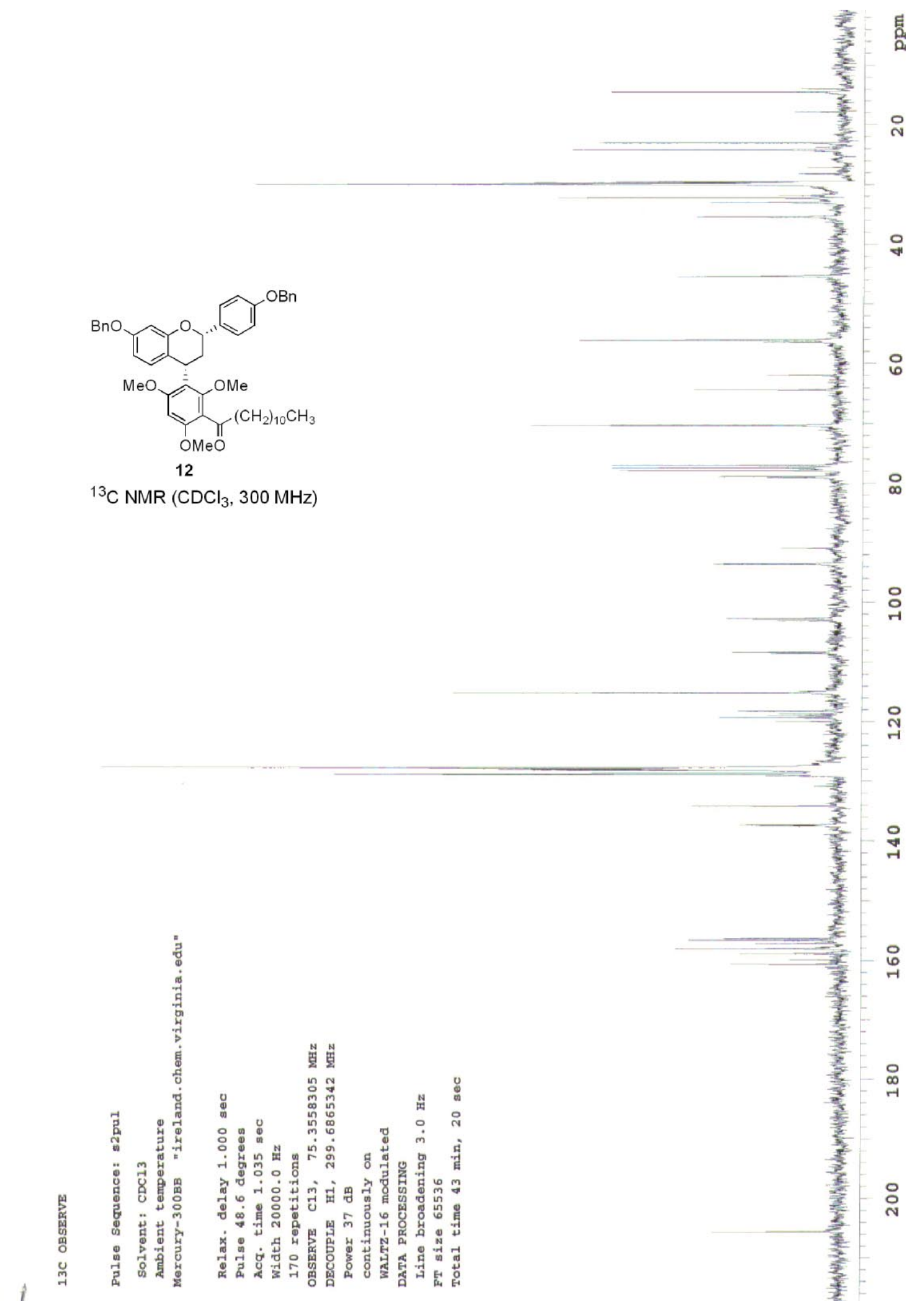




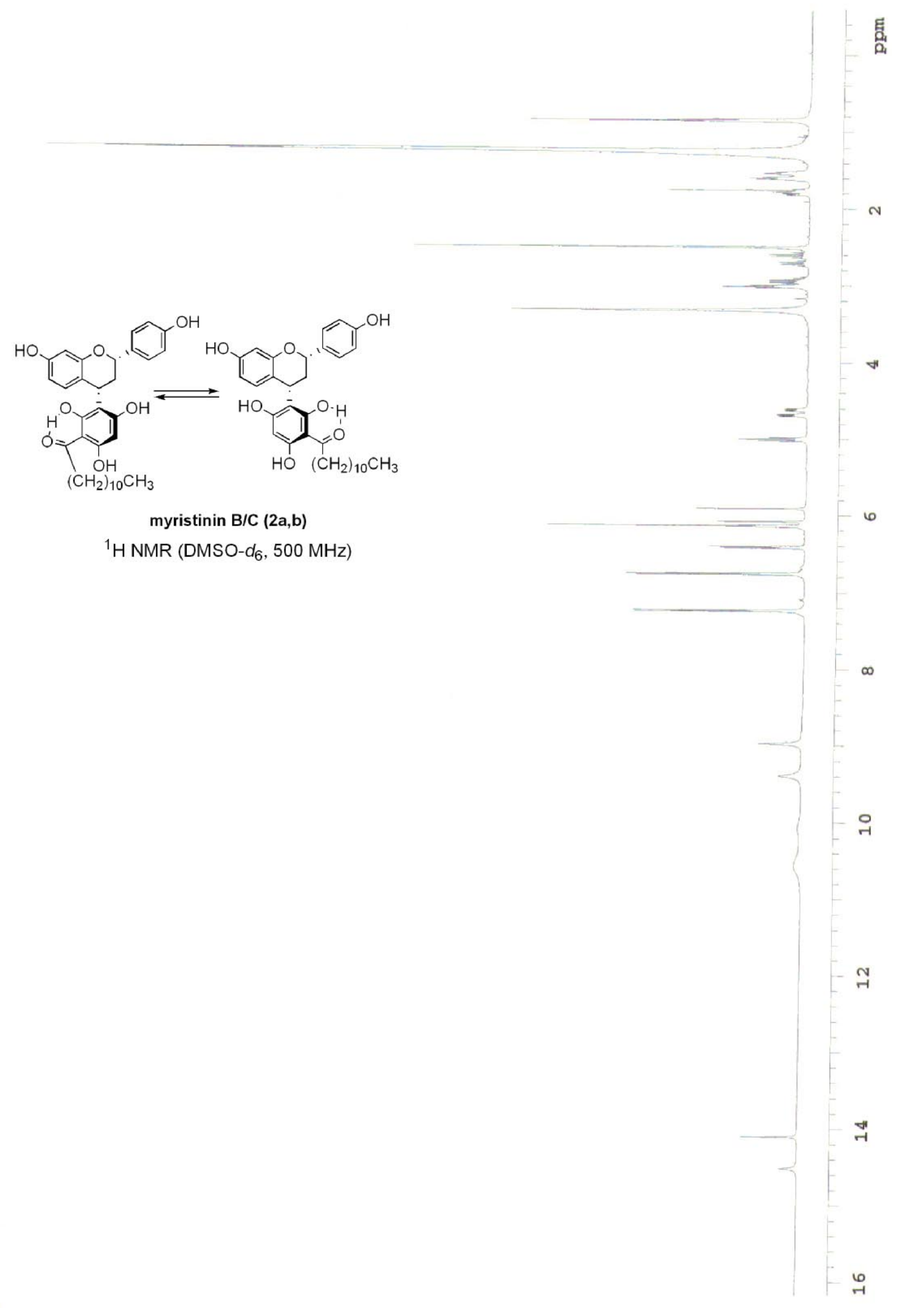




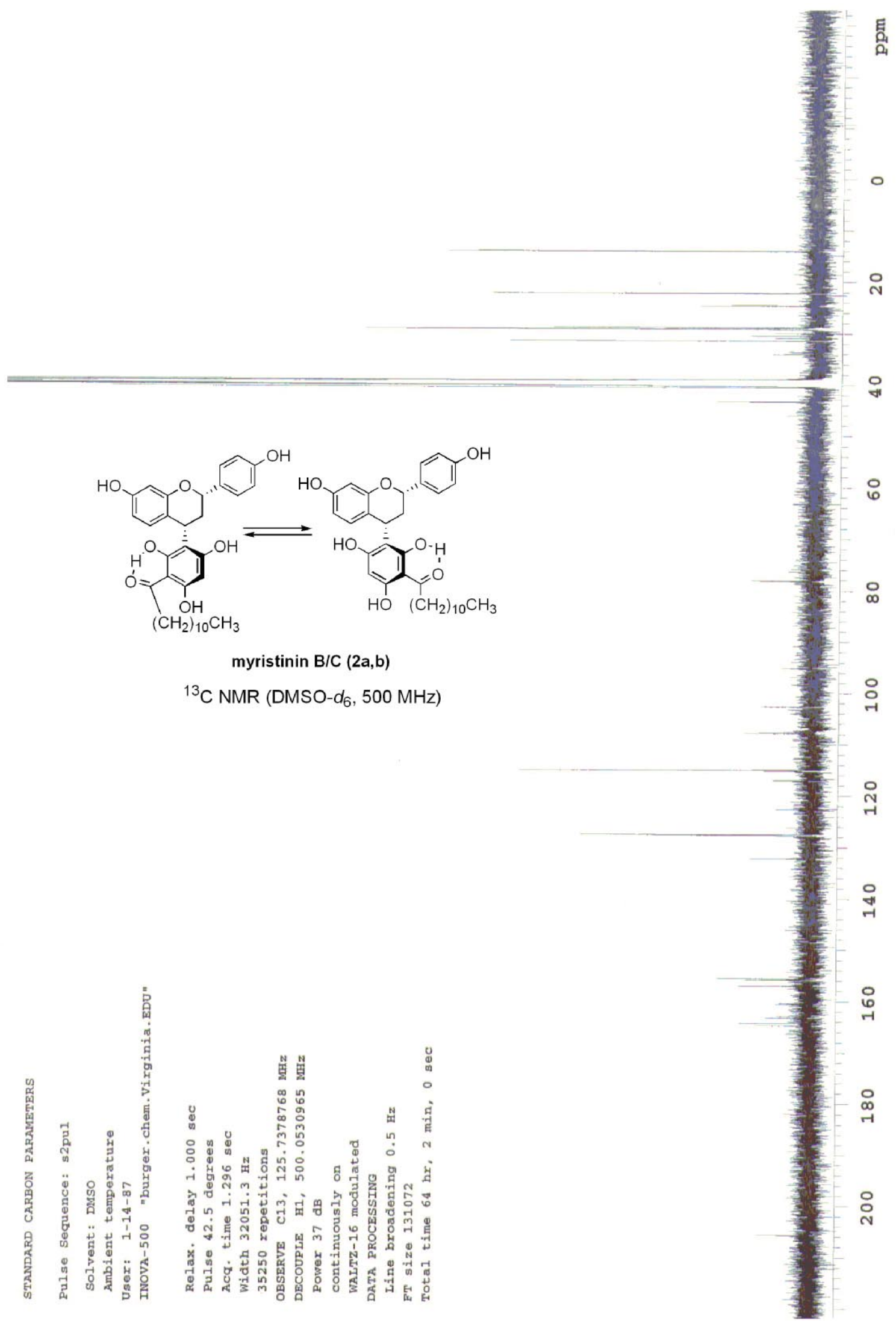



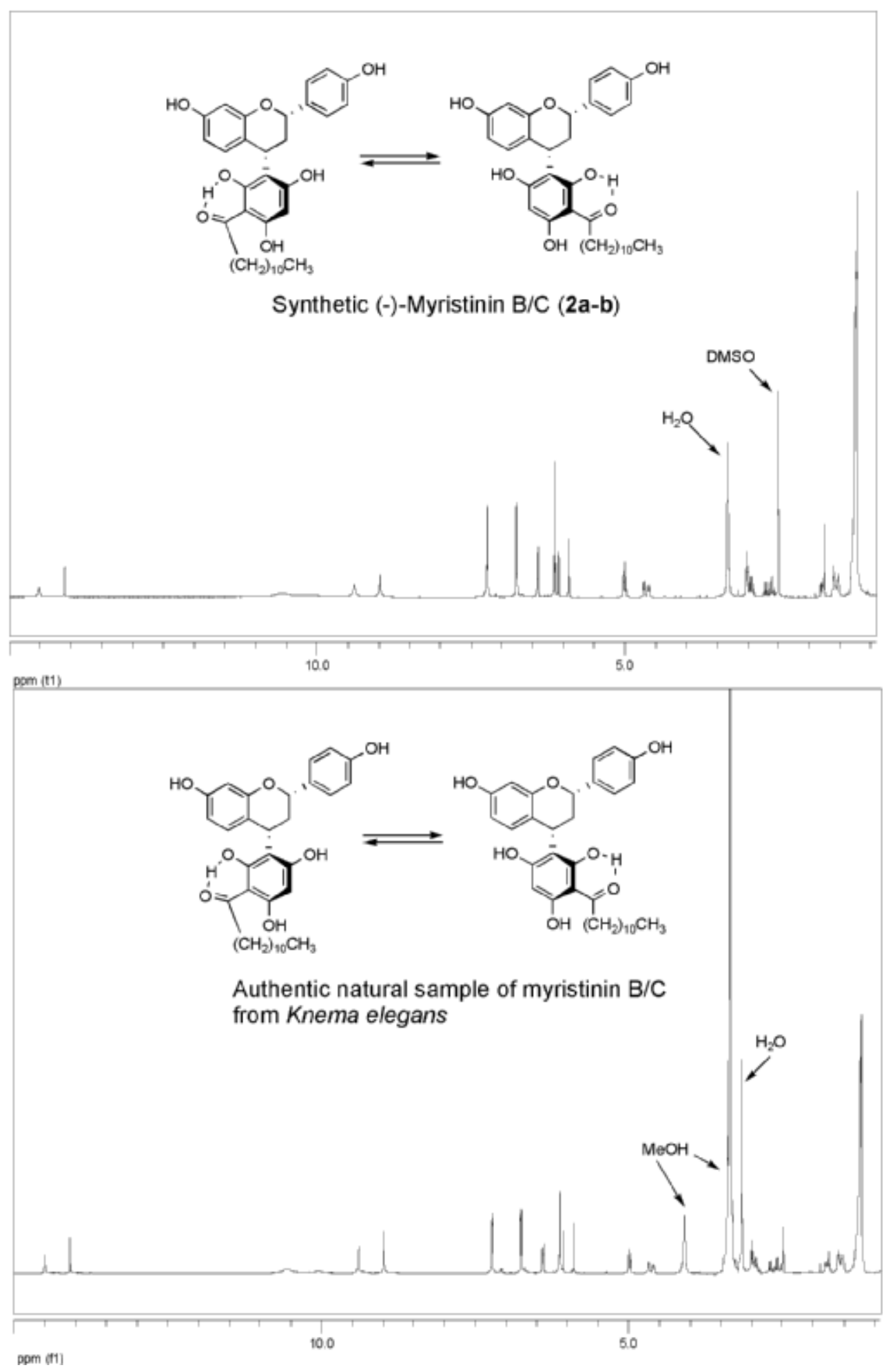


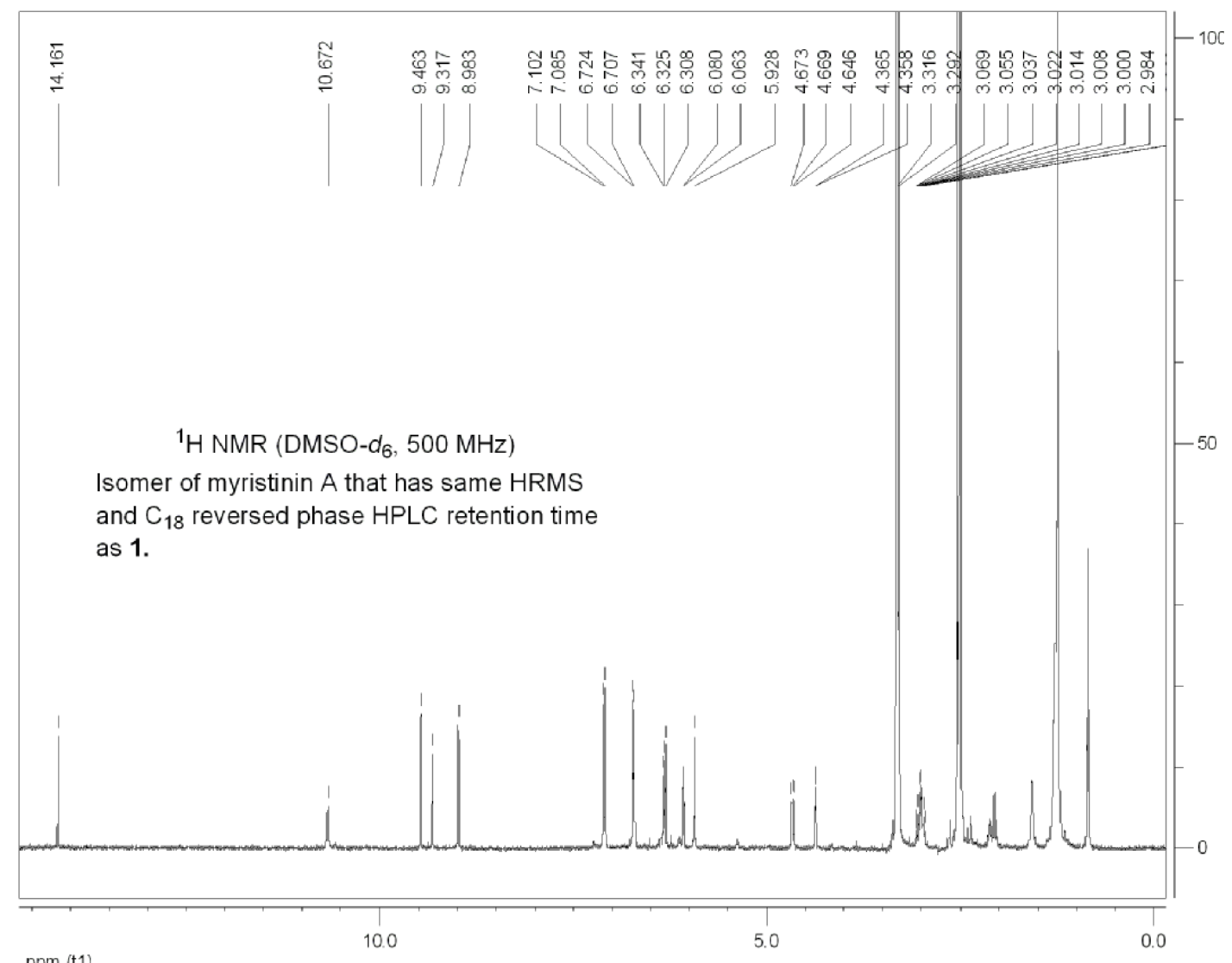

ppm (t1)

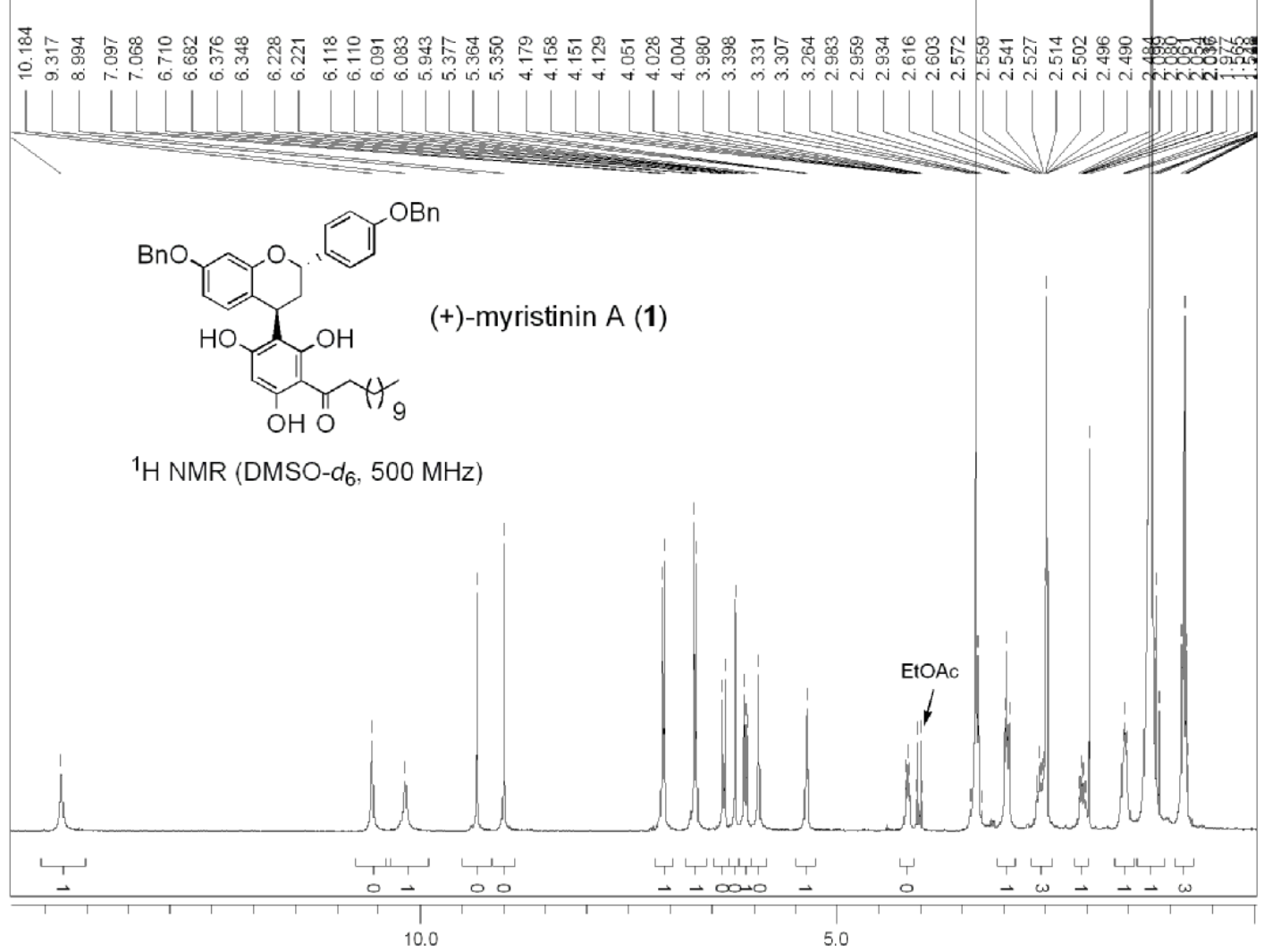

ppm (t1) 